\title{
Synchrotron X-ray Studies of Austenite and Bainitic Ferrite
}

\author{
By H. J. Stone, M. J. Peet, H. K. D. H. Bhadeshia, P. J. Withers ${ }^{\ddagger}$, \\ S. S. BaBU ${ }^{\dagger}$ AND E. D. SPEChT \\ Materials Science and Metallurgy, University of Cambridge \\ Cambridge CB2 3QZ, U.K. \\ $\dagger$ Industrial, Welding, and Systems Engineering \\ Ohio State University, Columbus, Ohio 43221, USA \\ ${ }^{\ddagger}$ School of Materials, University of Manchester, Manchester M1 7HS, U.K. \\ ๑ Oak Ridge National Laboratory, Tennessee 37831, USA.
}

\begin{abstract}
High resolution synchrotron $\mathrm{X}$-ray diffraction has been used to conduct in situ studies of the temporal evolution of phases during the isothermal growth of bainite. Two populations of austenitic material were identified: one corresponding to the initial austenite, the other to the carbon-enriched austenite associated with the bainitic ferrite. The observed lattice parameters and the asymmetry of the peaks from the residual austenite have been interpreted in terms of the carbon partitioning due to the transformation. The results are contrasted with an earlier study in which the austenite unit cell appeared to split into two distinct densities prior to the onset of transformation.
\end{abstract}

\section{Introduction}

There is considerable interest in the atomic mechanism of the bainite transformation in steels, given the dramatic developments in the application of the phase in a variety of contexts (Abe, 2004; Anonymous, 2004; DeCooman, 2004; Jacques, 2004; Klueh, 2004; Yang and Fang, 2005). There is also a demonstrated potential for major further developments (Caballero and Bhadeshia, 2005; Caballero et al., 2001a,b, 2002; Chatterjee et al., 2007; Garcia-Mateo et al., 2003a,b; Speer et al., 2004). The topic has been the subject of intense research with the bainite transformation exposed to a variety of advanced experimental probes.

High-intensity X-rays experiments using synchrotron facilities are in this context particularly interesting. They enable accurate data such as lattice parameters, phase fractions and other details related to strain and homogeneity to be collected during the course of transformations in steels (Babu et al., 2002, 2005; Elmer et al., 2004).

One such study in which several of the present authors were involved (Babu et al., 2005) revealed a peculiar and as yet unexplained phenomenon, that the facecentred cubic (FCC) crystal structure of the parent austenite splits into two identi- 
cal FCC lattices but with different lattice parameters before it begins to transform to bainite Fig. 1 . The experiments utilised an alloy in the $\mathrm{Fe}-0.8 \mathrm{C}-1.5 \mathrm{Si}-2 \mathrm{Mn}$ wt\% system because the slow rate of reaction to bainite enables the experiment to be done easily. However, this alloy system is also an important one for study because the bainite transformation can be suppressed to temperatures as low as $125^{\circ} \mathrm{C}(\mathrm{Ca}-$ ballero et al., 2002). The result is an incredibly fine two-phase microstructure of just bainitic ferrite and carbon-enriched retained austenite - the plates of bainite are only 20-40 nm in thickness (Bhadeshia, 2005b; Brown and Baxter, 2004; Caballero et al., 2002). This already has provided a viable production route to cheap, bulk nanostructured materials with an attractive combination of properties.

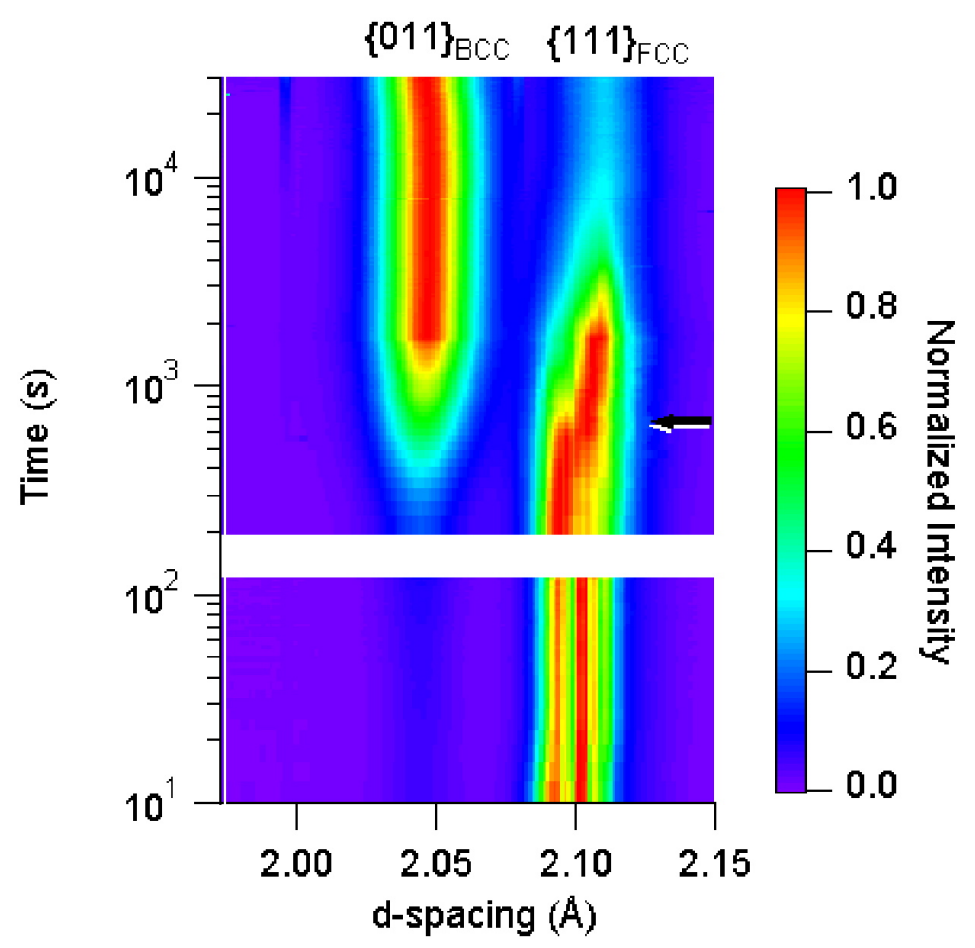

Figure 1. Diffraction data (Babu et al., 2005) showing in the lower part of the figure, that at small times before the onset of the bainite reaction, the austenite appears to have two different lattice parameters during isothermal holding at the transformation temperature. 'BCC' stands for the body-centred cubic form of iron.

The purpose of the present work was therefore to investigate using the synchrotron facility at Grenoble, the kinetics of the transformation to nanostructured bainite with the simultaneous aim of studying further any precursor events in the parent austenite prior to transformation. The equipment used had a much higher resolution and a different detector system than the original Argonne experiments. 
Table 1. Chemical compositions of alloys investigated, in wt\%.

\begin{tabular}{lccccccccc}
\hline Alloy & Fe & $\mathrm{C}$ & $\mathrm{Si}$ & $\mathrm{Mn}$ & $\mathrm{Mo}$ & $\mathrm{Cr}$ & $\mathrm{V}$ & $\mathrm{Co}$ & $\mathrm{Al}$ \\
Alloy 1 & balance & 0.79 & 1.56 & 1.98 & 0.24 & 1.01 & - & 1.51 & 1.01 \\
Alloy 2 & balance & 0.75 & 1.63 & 1.95 & 0.29 & 1.48 & 0.1 & - & $<0.01$ \\
\hline
\end{tabular}

\section{Experimental Details}

(a) Sample

An alloy, designated Alloy 1 (Table 1) based on the Fe-0.8C-1.5Si-2Mn wt\% system was selected including additions of cobalt and aluminium. These additions are known to slightly accelerate the bainite reaction to enable experiments to be done in a reasonable time period consistent with synchrotron availability (GarciaMateo et al., 2003a). The alloy is also important from a technological perspective (Bhadeshia, 2005b) and is the main focus of the work reported here. A particular experiment needed to be conducted on Alloy 2 (Table 1), which is described towards the end of the paper. However, unless specifically mentioned, all the experiments and analyses refer to Alloy 1.

Alloy 1 was homogenised for $48 \mathrm{~h}$ at $1200^{\circ} \mathrm{C}$, and transformed to bainite at $250^{\circ} \mathrm{C}$. A cylindrical specimen $1.5 \mathrm{~mm}$ diameter by $5 \mathrm{~mm}$ long was cut from the previously transformed sample using electro-discharge machining followed by abrasion with a 400 grit $\mathrm{SiC}$ paper. With the $60 \mathrm{keV} \mathrm{X-rays} \mathrm{used} \mathrm{the} \mathrm{signals} \mathrm{originate}$ from the entire thickness of the specimen rather than just the surface regions.

During the present synchrotron experiments (described later), the sample was austenitised at $832^{\circ} \mathrm{C}$ rather than the $1000^{\circ} \mathrm{C}$ used in the original experiments (Babu et al., 2005). This leads to a reduction in the austenite grain size by a factor of about 2 (Garcia-Mateo et al., 2003a), which is useful in order to improve the counting statistics of integrated peak profiles. The fact that in the present work the whole sample volume is penetrated by the $\mathrm{X}$-rays and that the sample is spun about its axis also helps in this respect.

\section{(b) Synchrotron $X-$ ray diffraction}

The temporal evolution of phases during the bainite reaction was characterised in-situ using synchrotron X-radiation and the ID31 high-resolution powder diffractometer at the European Synchrotron Radiation Facility (ESRF) in Grenoble, France. Diffraction data are acquired using a 9 detector array. Each detector consists of a Si $\{111\}$ analyser crystal and a Y-Al perovskite scintillator crystal viewed by a multi-stage photo-multiplier tube. The individual detectors are separated by $2^{\circ}$ in $2 \theta$.

By sweeping this array through a range of $2 \theta$ greater than the angular separation of the individual detectors, overlapping frames of diffraction spectra are acquired from each detector. These are normalised according to the efficiency of each detector and averaged to generate a single diffraction pattern. The quality of the diffraction spectra obtained in this fashion may be improved by increasing the number of detectors which observe a given range of $2 \theta$ or by decreasing the scan rate. Where studies are performed on systems with a characteristic time comparable to that required to reliably acquire a spectrum, as in this study, compromises must be 
made on the degree of frame overlap and scan rates to ensure that the data are acquired with adequate time resolution.

A nominal incident beam energy of $60 \mathrm{keV}$ was selected through diffraction from a double-crystal $\mathrm{Si}\{111\}$ monochromator. Initial calibration measurements were performed on $\mathrm{Si}$ and $\mathrm{Na}_{2} \mathrm{Ca}_{3} \mathrm{Al}_{2} \mathrm{~F}_{14}$ (NAC) standard powders. Measurements were made scanning the central crystal of the array through $6^{\circ} \leq 2 \theta \leq 30^{\circ}$ at $1^{\circ} \mathrm{min}^{-1}$. Where frame overlap occurred, comparison of the diffraction signal recorded by each detector crystal allowed their relative efficiencies to be determined and hence enabled a normalisation table to be obtained for subsequent measurements. From the diffraction data acquired with the Si powder standard, the wavelength of the incident beam was determined to be $0.20666 \pm 0.00001 \AA$ from the measured positions of the first 10 peaks. The data acquired in these calibration measurements were also used for later analysis of peak shape to determine the resolution of the instrument in this configuration.

For temporal phase-evolution measurements only the central 5 crystals of the detector array were sufficient to capture the angular range of interest. For these measurements, the central crystal was scanned from $8.8^{\circ} \leq 2 \theta \leq 11.0^{\circ}$ at $2^{\circ} \mathrm{min}^{-1}$. This provided data from $4.8^{\circ} \leq 2 \theta \leq 15.0^{\circ}$ from the central 5 crystals and had limited frame overlap. Acquisition times for each scan were $66 \mathrm{~s}$ after which $7 \mathrm{~s}$ were required to rotate the detector back to the start position.

During testing, the sample was located in a sealed glass-capillary to avoid oxidation. A small piece of platinum wire alongside the sample provided a temperature reference via its lattice parameter and calibration data, Figure 2. The sample assembly was spun at $3000 \mathrm{rpm}$ during diffraction to increase the population of grains contributing to the measured pattern and thereby improve the detected signal.

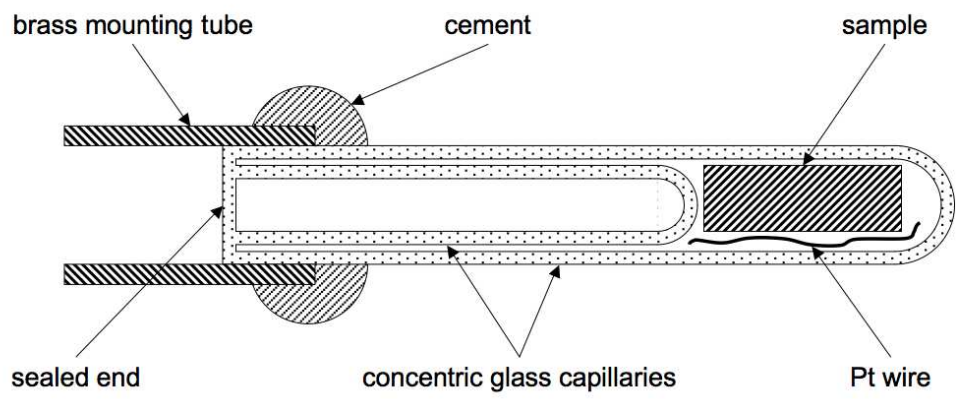

Figure 2. The sample assembly.

Two hot air blowers were mounted on a translation stage directly beneath the sample assembly, with exit gas temperatures set to $1050^{\circ} \mathrm{C}$ (blower-A) and $350^{\circ} \mathrm{C}$ (blower-B) respectively, as determined by K-type thermocouples positioned at the mouth of each blower (Figure 3). Subsequent comparison with data from the platinum wire indicated that the corresponding sample temperature when positioned above air blower- $\mathrm{A}$ was $832 \pm 5^{\circ} \mathrm{C}$ and $300 \pm 1^{\circ} \mathrm{C}$ when positioned over air blower- $\mathrm{B}$.

The sample was austenitised for approximately 30 min above air blower-A, 


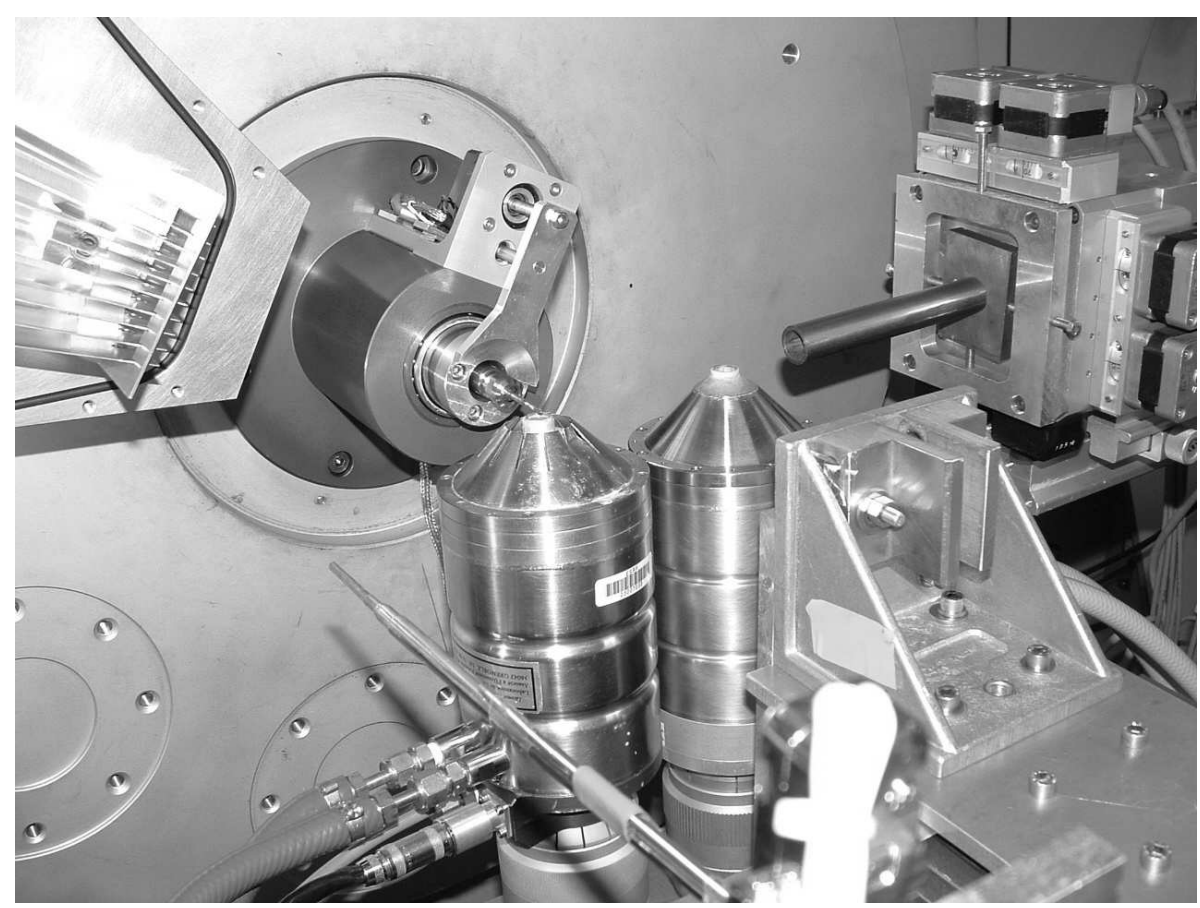

Figure 3. Sample assembly mounted on the ID31 diffractometer hot-air blowers positioned underneath.

whilst acquiring diffraction data to confirm full austenitisation. Blower-B was then quickly $(4.96 \mathrm{~s})$ positioned beneath the sample by translation; the sample continued to glow at the point of entry into the cooler gas stream indicating that no significant undercooling occurred during the translation. In this position, diffraction data were acquired continuously until the bainite reaction was observed to cease. During this isothermal dwell the sample temperature remained at $300.5^{\circ} \mathrm{C}$ with a standard deviation of $1.3^{\circ} \mathrm{C}$ and maximum / minimum recorded excursions of $\pm 3^{\circ} \mathrm{C}$.

\section{Results and Discussion, Alloy 1}

\section{(a) Instrumental resolution}

The diffraction data acquired from the Si \& NAC standard powders were partitioned into $0.0003^{\circ}$ bins in $2 \theta$. The peaks were fitted with a Voigt function (Langford, 1978), implemented as a numerical convolution (Gold, 1975) between normalised Gaussian and Lorentzian functions. This was further convolved with an axial divergence function (Finger et al., 1994), to account for the asymmetry of the peak arising as a result of finite detector and sample size.

Figure 4a shows that the width of the Gaussian component of the Voigt function for Si and NAC is on the same trend. This is expected since the Gaussian contribution to peak broadening arises predominantly from instrumental effects and is therefore sample independent. Furthermore, the data were readily fitted with a quadratic function in $\tan \theta$ (dotted line, Figure 4a) consistent with the angular 
$(\mathrm{a}, \mathrm{b})$
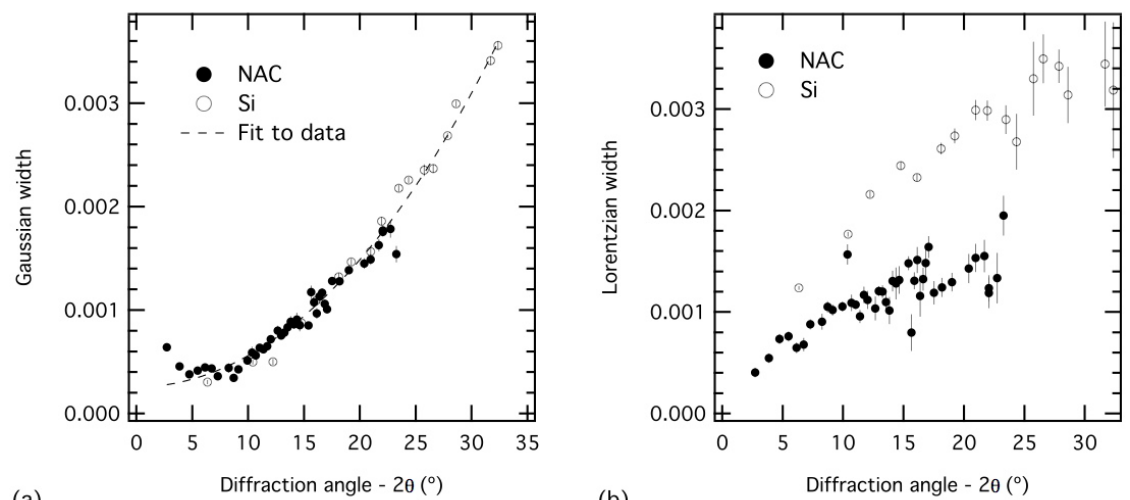

(a)

(b)
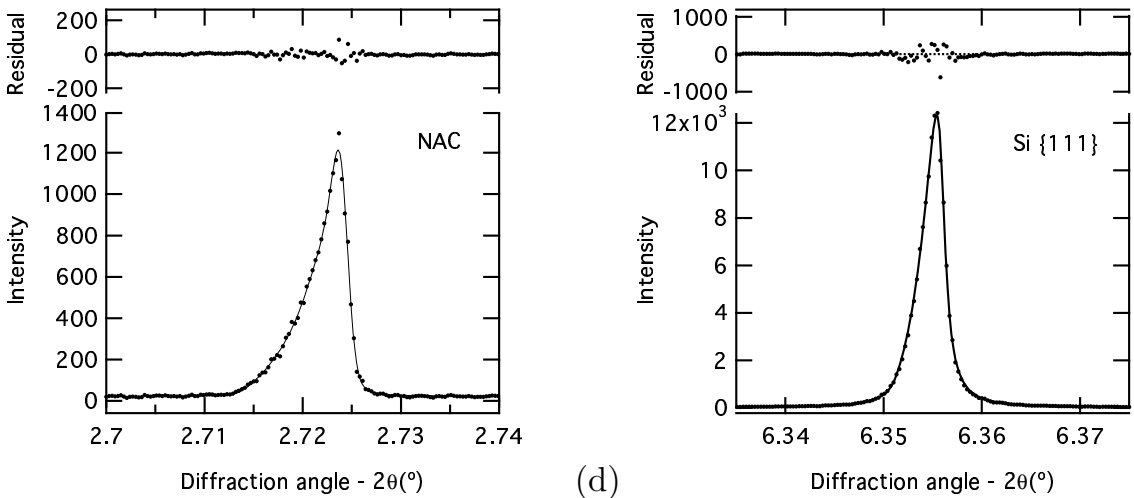

Figure 4. (a) Gaussian and (b) Lorentzian widths of the Voigt functions fitted to the individual peaks in the diffraction spectra obtained from the Si and NAC powders. (c,d) Illustration of the excellent fit obtained with the asymmetric peaks of NAC and Si calibration samples after convolving with the axial divergence function.

divergence associated with collimation for crystal spectrometers (Caglioti et al., 1958). In contrast, the Lorentzian components are different for the two powders, because they depend on sample characteristics such as particle size and heterogeneous strain (Figure 4b). The success in reproducing the asymmetry of the peaks using the axial divergence function is illustrated in Figure 4c,d.

If the Lorentzian component of the inherent instrumental resolution is taken as being at least as narrow as the data acquired from the NAC diffraction spectra, then the limiting angular separation of diffraction peaks to be separately resolved is about $0.0018^{\circ}$ at $2 \theta=5.6^{\circ}$ - the lowest angle at which diffraction data are acquired. This corresponds to an equivalent separation of lattice plane spacing of $0.0003 \AA$ or a resolution of approximately $0.0005 \AA$ in the lattice parameter. 


\section{(b) Evolution of spectra during transformation}

The diffraction data obtained during transformation were partitioned into $0.002^{\circ}$ bins in $2 \theta$. No significant variations were observed on the time-scale of individual scans $(\sim 73 \mathrm{~s})$. Subsequent analysis was therefore performed on data sets consisting of the sum of 5 consecutive scans to improve counting statistics.

Figure 5 shows examples from the austenite $\{111\}$ and ferrite $\{110\}$ during transformation. The initial pattern consisted of narrow peaks exclusively from austenite. Their intensity decreased as transformation progressed. In addition, broad ferrite peaks appeared along with a second set of broad austenite peaks at lower $2 \theta$ angles than the initial ones. The latter is caused by the partitioning of carbon from the bainite into the residual austenite, thereby leading to an increase in its lattice parameter (Bhadeshia, 2001). The partitioned carbon is heterogeneously distributed, leading to the two sets of austenite peaks (the enriched and un-enriched austenite). This is also the reason why the intensity associated with the largerparameter (carbon rich) austenite increases in parallel with that of bainitic ferrite.

The carbon concentration gradients, together with the nonuniform strains associated with the displacive formation of bainite are responsible for the broad peaks following the commencement of transformation. The richest austenite is that present as 'films' between platelets of bainitic ferrite, and the 'blocks' of austenite are those which are relatively poor in carbon (Bhadeshia and Waugh, 1982; Le-Houillier et al., 1971; Matas and Hehemann, 1961).

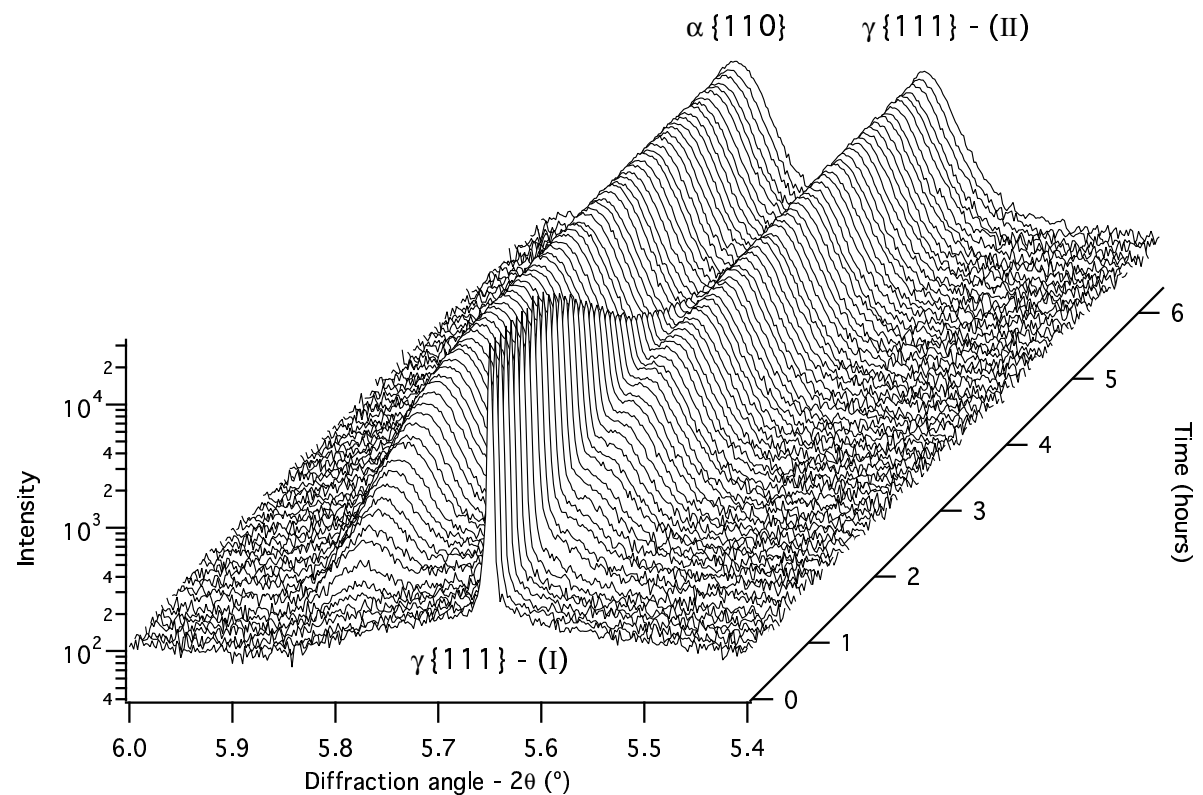

Figure 5. Austenite $\{111\}$ and ferrite $\{110\}$ peaks during isothermal heat-treatment at $300^{\circ} \mathrm{C}$ following austenitisation. Notice that intensity is plotted on a logarithmic scale. 


\section{(c) Diffraction peak fitting}

The bainitic ferrite peaks and the initial sharp austenite peaks were fitted with Voigt functions (Langford, 1978) convolved with an axial divergence function (Finger et al., 1994) as described previously. However, the broadened secondary austenite peaks that accompany the development of the bainitic ferrite exhibited a further asymmetry, trailing towards low $2 \theta$, which could not be adequately described in this way, but required a further convolution with an exponential function from zero to the peak position.

Examples of the fitted data obtained at a number of temperatures during the isothermal dwell at $300^{\circ}$ are given in Figure 6.

\section{(d) Calculation of phase fractions}

Phase fractions were determined from the diffracted intensities $\left(I_{\circ}^{h k l}\right)$, accounting for the Lorentz-polarisation $(L P(\theta))$, the Debye-Waller factor $(\exp \{-2 M\})$, the structure factor $\left(|F|^{2}\right)$ and multiplicities $(p)$ of the individual peaks:

$$
I_{\circ}^{h k l}=I^{h k l} p|F|^{2} \exp (-2 M) L P(\theta)
$$

where $I^{h k l}$ is the absolute intensity.

For austenite, $\left|F_{\gamma}\right|^{2}=(4 f)^{2}$ where $f$ is the atomic scattering factor of an atom of iron. Similarly, $\left|F_{\alpha}\right|^{2}=(2 f)^{2}$.

As the synchrotron radiation is essentially fully polarised in the axial direction there is no angular dependence of the polarisation on the measured intensity so the Lorentz-polarisation factor is simply $L P(\theta)=(\sin \theta \sin 2 \theta)^{-1}=\left(2 \sin ^{2} \theta \cos \theta\right)^{-1}$.

In the Debye-Waller factor, $M=B(\sin \theta / \lambda)^{2}$ where $B=8 \pi^{2}\left\langle\bar{u}_{x}^{2}\right\rangle$ in which $\left\langle\bar{u}_{x}^{2}\right\rangle$ is the time-averaged mean-square displacement of scattering atom along the direction of the reciprocal lattice vector of the reflection $h k l$. If the vibrations are assumed to have spherical symmetry this term does not vary with $\theta$ and may be assumed constant for a given temperature and material. Using the Debye approximation for this coefficient

$$
B=\frac{6 h^{2} T}{m k \Theta^{2}}\left(\frac{1}{x} \int_{0}^{x} \frac{\xi}{\exp (\xi)-1} d \xi+\frac{x}{4}\right) \quad \text { where } \quad x=\frac{\Theta}{T}
$$

in which, $h$ is Planck's constant, $k$ is Bolzmann's constant, $T$ is the sample temperature in $\mathrm{K}, m$ is the average atomic mass and $\Theta$ is the Debye temperature of the material.

Phase fractions were determined by taking the ratio of the corrected peak intensity for each species to the sum of all the peaks observed, Figure 7.

Bainitic ferrite develops rapidly within the first few hours, reaching a final fraction of approximately 0.83 . The proportion of film austenite increases simultaneously, maintaining a ratio of about 4.5:1 with the bainitic ferrite, reaching a final fraction of about 0.17 . The bulk austenite at the same time tends towards zero. Consistent with the incomplete reaction phenomenon, the maximum fraction of bainite obtained is far less than expected from thermodynamic equilibrium (Bhadeshia and Edmonds, 1979a, 1980). The larger error bars at the end of the test (Figure 7) are attributed to the difficulty in obtaining reliable fit in this region as the fraction of bulk austenite tends to zero. 
During the early stages of transformation, the lattice parameter of the higher carbon films of austenite is greater than what it is towards the end of transformation as the carbon that is partitioned from the supersaturated ferrite diffuses over longer distances (Figure 8). The carbon enrichment is greatest in the vicinity of the bainite plates, with distant blocky-austenite affected little, thus giving rise to the bimodal austenite parameters (Bhadeshia and Edmonds, 1979b). The two values approach each other during the late stages of transformation as the blocky austenite itself diminishes in scale and evolves into films as the bainite penetrates it. The carbon concentrations of the two austenite regions (Figure 8) are calculated from the lattice parameters assuming that the latter varies by $0.0330 \times$ wt.\%C (Dyson and Holmes, 1970).

The carbon is not homogeneously distributed in the remaining austenite, localising near the bainite plates where significant concentration gradients are expected (Mujahid and Bhadeshia, 1992). These gradients may explain the asymmetry observed in the diffraction peaks associated with the carbon-rich regions of austenite. However, the degree of asymmetry of these peaks does not vary appreciably during the transformation to an extent that could be detected in the fitted peak profiles. It is therefore likely that the asymmetry arises as a result of differences in average carbon concentration of separate regions of austenite rather than local variations within individual regions; this is consistent with high-resolution measurements of the carbon distribution (Bhadeshia and Waugh, 1982; Caballero et al., 2007; Self et al., 1981). This is reasonable, as observations of this type of microstructure indicate that sheaves form with a significant variation in the size of austenite regions trapped between ferrite platelets (Chang and Bhadeshia (1995) and Section e).

A similar, but much smaller variation can be seen in the lattice parameter of the bainitic ferrite. During the period of more rapid transformation, the lattice parameter of the bainitic ferrite is observed to decrease from $2.8820 \pm 0.0003 \AA$ to $2.8814 \pm 0.0005 \AA$. This variation is approximately 3.5 times greater than can be explained by the drift in sample temperature during isothermal transformation. Using the composition dependence of the lattice parameter in bainitic ferrite (Bhadeshia et al., 1991) this corresponds to a plausible change in the carbon content of bainitic ferrite by 0.013 wt.\%. Bainitic ferrite has been shown to contain excess carbon (Bhadeshia and Waugh, 1982; Caballero et al., 2007; Peet et al., 2004) so that some redistribution is expected.

\section{(e) Microstructure}

The sample microstructure obtained after completion of the test using a JEOL 6340F FEGSEM following polishing and etching with nital is given in Figure 9. It consists of bainitic ferrite and retained austenite, the latter in the form of films and blocks between the sheaves. No perceptible variations in the microstructure were observed across the sample or towards the surface; there were no signs of chemical segregation or decarburisation. It is worth emphasising that at $60 \mathrm{keV}$, the beam penetration is of the order of millimetres so the results should not be sensitive to surface effects. 


\section{Comparison with Previous Work}

Part of this work was inspired by the need to verify previous as yet unexplained observations that the austenite as a precursor to phase transformation decomposes into two unit cells of with different lattice parameters (Babu et al., 2005). The decomposition manifests as the splitting of $\mathrm{X}$-diffraction peaks as illustrated in Fig. 1.

The resolution with which the present experiments have been conducted is about twenty times that of previous work. If peak splitting exists then it can be detected with greater confidence. A trial split-peak is illustrated in Fig. 10a,d, which is then convolved with the resolution function of the present (Fig. 10b) and previous (Fig. 10e) works, produced the expected outcomes as illustrated in Fig. 10c,f.

Fig. 11 shows in a different format and covering a broader range of Bragg angles, the same data as presented in Fig. 5. This is to emphasise that there is no austenite peak splitting to be seen before the onset of the bainite reaction. The question therefore remains as to why the earlier experiments contradict this conclusion.

One possibility is that the apparent splitting is an artefact introduced in the process of correcting the data for detector tilt and in the location of the centre of the pattern observed using the area detector (Babu et al., 2005). An example of the original, raw data is presented in Fig. 12, representing the austenite prior to its transformation. It is a case in which the final plot in the form presented in Fig. 1 revealed austenite peak-splitting. It is clear however that the raw data do not within the limits of resolution show double rings associated with the expected locations of diffraction peaks from a single lattice. It is possible that within these limits, individual spots in an apparently single ring could originate from crystals of austenite with unit cells of different densities. However, this would require an unlikely explanation of why the lattice parameter should vary between grains of austenite.

As Fig. 12 illustrates, there is a limited number of crystallites fulfilling the Bragg condition and contributing to the diffraction 'rings', making them spotty. When a ring consists mostly of a few strong, sharp reflections, integration will yield a peak profile dominated by those few peaks within the envelope of the instrumental resolution. Line-shape analysis of the integrated profile then becomes unreliable.

For this reason, we have taken a set of data from similar experiments done on an $\mathrm{Fe}-\mathrm{Ni}-\mathrm{C}$ alloy where peak splitting has also been observed (Babu et al., 2007), and subjected it to analysis in which deliberate distortions are introduced during the integration of the diffraction rings into peaks, as illustrated in Fig. 13.

The integrated diffraction data obtained with optimal beam centre and tilt plane orientation angles are presented in Fig. 13a. This shows a single, approximately symmetric, narrow peak. By shifting the beam centre 10 pixels in the horizontal direction from the optimal position, the peak displays pronounced asymmetry and appears to be composed of multiple sub-peaks, see Fig. 13b. A similar degradation in the peak profile can also be obtained after integration with a $5^{\circ}$ increase in the magnitude of the tilt of the detector.

Comparison of the detector beam centre and tilt angles used in the analysis of 59 studies on austenitic-steel samples in earlier studies (Specht, 2007) showed a variation in the beam centre in the horizontal direction with a standard deviation of some 2 pixels and differences between the maximum and minimum if 8 pixels. 
Similarly, the variation in the beam centre in the vertical direction had a standard deviation of 3 pixels and differences between the maximum and minimum of 12 pixels. The magnitude of the tilt of the detector varied with a standard deviation of approximately $1^{\circ}$ with a difference between the maximum and minimum of $5^{\circ}$. As such, the degree of distortion artificially introduced in the analysis presented in Fig. 13 is consistent with the maximum likely to be seen in the experiments previously conducted and is likely to be larger than expected distortions by a factor of $3-5$.

This analysis does, however, show that the integration procedure can introduce artefacts into the peak shape including asymmetries and doublets which could be interpreted as peak splitting. Any peak which is genuinely split cannot be un-split by introducing reasonable levels of tilt and centring errors; the fact that single peaks can be obtained (Fig. 13) strengthens the case for the absence of peak splitting in the original data.

\section{Long-Time Experiment, Alloy 2}

Alloy 2 was used in our original experiments (Babu et al., 2005) which indicated precursor phenomena in the austenite. The isothermal transformation was in those experiments conducted at $300^{\circ} \mathrm{C}$. One major advantage of this alloy is its very slow transformation rate at even lower temperatures (Caballero et al., 2002), permitting the state of the austenite to be studied without any possibility of interference from phase changes. We therefore conducted experiments on the austenite at $200^{\circ} \mathrm{C}$, where the initiation of transformation takes days. The results are illustrated in Fig. 14 which clearly shows that there is no peak splitting in the austenite during approximately $10 \mathrm{~h}$ at the transformation temperature.

\section{Conclusions}

High resolution diffraction indicates that two populations of austenite evolved during the course of transformation. One corresponds to the initial austenite, the other to the carbon-enriched variety that remains untransformed between sub-units of bainitic ferrite and between adjacent sheaves.

During the period of relatively rapid changes in volume fraction, the austenite richer in carbon (thin films) exhibits a larger lattice parameter than towards the end of reaction. This is consistent with the carbon partitioning behaviour.

The diffraction peaks associated with the austenite left after the formation of bainite exhibit an asymmetry that cannot be accounted for by instrumental effects. This is attributed to a heterogeneous distribution of carbon in different regions of austenite because it takes time for carbon to homogenise after it is partitioned from supersaturated bainitic ferrite. The extent of asymmetry is constant during the course of transformation, indicating that there are separated regions of austenite with different carbon concentrations.

The high-resolution experiments reported here show that there is no division of austenite into two lattice parameter unit cells as a precursor to phase transformation during isothermal heat-treatment. It is believed that previous much lowerresolution experiments which contradict the present observations also do not show 
peak-splitting when the raw data are reconsidered. It is likely that the integration of data introduces peak-splitting as an artefact of analysis.

The present work proves that the austenite remains homogeneous prior to bainitic transformation, and that the reaction remains thermodynamically incomplete. The results therefore provide further support for a mechanism in which bainite growth is diffusionless, with carbon partitioning occurring subsequent to transformation (Bhadeshia, 2005a; Bhadeshia and Edmonds, 1979a, 1980; Chatterjee et al., 2006; Hehemann, 1970; Ko and Cottrell, 1952; Matsuzaki et al., 1994; Swallow and Bhadeshia, 1996).

\section{Acknowledgements}

We are grateful to ESRF (Grenoble) for the synchrotron facilities and to the Engineering and Physical Sciences Research Council of the U.K. for funding the work on transformation plasticity, of which this work is a component. Support is acknowledged from the Division of Materials Sciences and Engineering, Office of Basic Energy Sciences, United States Department of Energy, under Contract No. DEAC05-00OR22725 with Oak Ridge National Laboratory, which is managed by UTBattelle.

\section{References}

Abe, F., 2004. Bainitic and martensitic creep-resistant steels. Current Opinion in Solid State and Materials Science 8, 313-321.

Anonymous, 2004. ADI solutions aid vehicle design. Foundary 178, 54-56.

Babu, S. S., Elmer, J. W., David, S. A., Quintana, M., 2002. In situ observations of nonequilibrium austenite formation during weld solidification of a FeCAlMn low alloy steel. Proceedings of the Royal Society A 458, 811-821.

Babu, S. S., Specht, E. D., David, S. A., Karapetrova, E., Zschack, P., Peet, M., Bhadeshia, H. K. D. H., 2005. In-situ observations of lattice parameter fluctuations in austenite and transformation to bainite. Metallurgical \& Materials Transactions A 36A, 3281-3289.

Babu, S. S., Specht, E. D., David, S. A., Karapetrova, E., Zschack, P., Peet, M., Bhadeshia, H. K. D. H., 2007. Time-resolved X-ray diffraction investigation of austenite and transformation to bainite. In: Suzaki, K., Furuhara, T. (Eds.), 1st International Symposium on Steel Science. Iron and Steel Institute of Japan, Iron and Steel Institute of Japan, Tokyo, Japan, pp. 1-7.

Bhadeshia, H. K. D. H., 2001. Bainite in Steels, 2nd edition. Institute of Materials, London.

Bhadeshia, H. K. D. H., 2005a. Developments in martensitic and bainitic steels: Role of the shape deformation. Materials Science and Engineering A 378, 34-39.

Bhadeshia, H. K. D. H., 2005b. Large chunks of very strong steel. Materials Science and Technology 21, 1293-1302.

Proceedings of the Royal Society A, Vol. 464, 2008, 1009-1027. 
Bhadeshia, H. K. D. H., David, S. A., Vitek, J. M., Reed, R. W., 1991. Stress induced transformation to bainite in a Fe-Cr-Mo-C pressure vessel steel. Materials Science and Technology 7, 686-698.

Bhadeshia, H. K. D. H., Edmonds, D. V., 1979a. The bainite transformation in a silicon steel. Metallurgical Transactions A 10A, 895-907.

Bhadeshia, H. K. D. H., Edmonds, D. V., 1979b. The bainite transformation in a silicon steel. Metallurgical Transactions A 10A, 895-907.

Bhadeshia, H. K. D. H., Edmonds, D. V., 1980. The mechanism of bainite formation in steels. Acta Metallurgica 28, 1265-1273.

Bhadeshia, H. K. D. H., Waugh, A. R., 1982. Bainite: An atom probe study of the incomplete reaction phenomenon. Acta Metallurgica 30, 775-784.

Brown, P. M., Baxter, D. P., 2004. Hyper-strength bainitic steels. In: Materials Science and Technology 2004. TMS, Warrendale, Pennsylvania, USA, pp. 433438.

Caballero, F. G., Bhadeshia, H. K. D. H., 2005. Very strong bainite. Current Opinion in Solid State and Materials Science 8, 186-193.

Caballero, F. G., Bhadeshia, H. K. D. H., Mawella, K. J. A., Jones, D. G., Brown, P., 2001a. Design of novel high-strength bainitic steels: Part i. Materials Science and Technology 17, 512-516.

Caballero, F. G., Bhadeshia, H. K. D. H., Mawella, K. J. A., Jones, D. G., Brown, P., 2001b. Design of novel high-strength bainitic steels: Part ii. Materials Science and Technology 17, 517-522.

Caballero, F. G., Bhadeshia, H. K. D. H., Mawella, K. J. A., Jones, D. G., Brown, P., 2002. Very strong, low-temperature bainite. Materials Science and Technology $18,279-284$.

Caballero, F. G., Miller, M. K., Babu, S. S., Garcia-Mateo, C., 2007. Atomic scale observations of bainite transformation in a high carbon high silicon steel. Acta Materialia 55, 381-390.

Caglioti, G., Paoletti, A., Ricci, F. P., 1958. Choice of coillimators for a crystal spectrometer for neutron diffraction. Nuclear Instruments 3, 223-228.

Chang, L. C., Bhadeshia, H. K. D. H., 1995. Austenite films in bainitic microstructures. Materials Science and Technology, 874-881.

Chatterjee, S., Murugananth, M., Bhadeshia, H. K. D. H., 2007. $\delta$-TRIP steel. Materials Science and Technology 23, 819-827.

Chatterjee, S., Wang, H. S., Yang, J. R., Bhadeshia, H. K. D. H., 2006. Mechanical stabilisation of austenite. Materials Science and Technology 22, 641-644.

DeCooman, B., 2004. Structure-properties relationship in TRIP steels containing carbide-free bainite. Current Opinion in Solid State and Materials Science 8, $285-303$. 
Dyson, D. J., Holmes, B., 1970. Effect of alloying additions on the lattice parameter austenite. Journal of the Iron and Steel Institute 208, 469-474.

Elmer, J. W., Palmer, T. A., Babu, S. S., Zhang, W., DebRoy, T., 2004. Direct observations of austenite, bainite, and martensite formation during arc welding of 1045 steel using time-resolved X-ray diffraction. Welding Journal, Research Supplement 83, 244s-253s.

Finger, L. W., Cox, D. E., Jephcoat, A. P., 1994. A correction for powder diffraction peak asymmetry due to axial divergence. Journal of Applied Crystallography 27, 892-900.

Garcia-Mateo, C., Caballero, F. G., Bhadeshia, H. K. D. H., 2003a. Acceleration of low-temperature bainite. ISIJ International 43, 1821-1825.

Garcia-Mateo, C., Caballero, F. G., Bhadeshia, H. K. D. H., 2003b. Development of hard bainite. ISIJ International 43, 1238-1243.

Gold, L. R. R. B., 1975. Theory and Application of Digital Signal Processing. Prentice-Hall.

Hehemann, R. F., 1970. The bainite transformation. In: Aaronson, H. I., Zackay, V. F. (Eds.), Phase Transformations. pp. 397-432.

Jacques, P. J., 2004. Transformation-induced plasticity for high strength formable steels. Current Opinion in Solid State and Materials Science 8, 259-265.

Klueh, R. L., 2004. Reduced-activation bainitic and martensitic steels for nuclear fusion applications. Current Opinion in Solid State and Materials Science 8, 239250 .

Ko, T., Cottrell, S. A., 1952. The formation of bainite. Journal of the Iron and Steel Institute 172, 307-313.

Langford, J. I., 1978. A rapid method for analysing the breadths of diffraction spectral lines using the voigt function. Journal of Applied Crystallography 11, $10-14$.

Le-Houillier, R., Begin, G., Dube, A., 1971. A study of the peculiarities of austenite during the bainite transformation. Metallurgical Transactions 2, 2645-2653.

Matas, S. J., Hehemann, R. F., 1961. The structure of bainite in hypoeutectoid steels. TMS-AIME 221, 179-185.

Matsuzaki, A., Bhadeshia, H. K. D. H., Harada, H., 1994. Stress-affected bainitic transformation in a Fe-C-Si-Mn alloy. Acta Metallurgica and Materialia 42, 10811090 .

Mujahid, S., Bhadeshia, H. K. D. H., 1992. Partitioning of carbon from supersaturated ferrite plates. Acta Metallurgica and Materialia, 389-396.

Peet, M., Babu, S. S., Miller, M. K., Bhadeshia, H. K. D. H., 2004. Threedimensional atom probe analysis of carbon distribution in low-temperature bainite. Scripta Materialia 50, 1277-1281.

Proceedings of the Royal Society A, Vol. 464, 2008, 1009-1027. 
Self, P. G., Bhadeshia, H. K. D. H., Stobbs, W. M., 1981. Lattice spacings from lattice fringes. Ultramicroscopy $6,29-40$.

Specht, E. D., 2007. Sixty CCD calibration data on austenitic samples studied at the APS, private Communication.

Speer, J. G., Edmonds, D. V., Rizzo, F. C., Matlock, D. K., 2004. Partitioning of carbon from supersaturated plates of ferrite, with application to steel processing and fundamentals of the bainite transformation. Current Opinion in Solid State and Materials Science 8, 219-237.

Swallow, E., Bhadeshia, H. K. D. H., 1996. High resolution observations of displacements caused by bainitic transformation. Materials Science and Technology 12, $121-125$.

Yang, Z. G., Fang, H. S., 2005. An overview on bainite formation in steels. Current Opinion in Solid State and Materials Science 9, 277-286. 

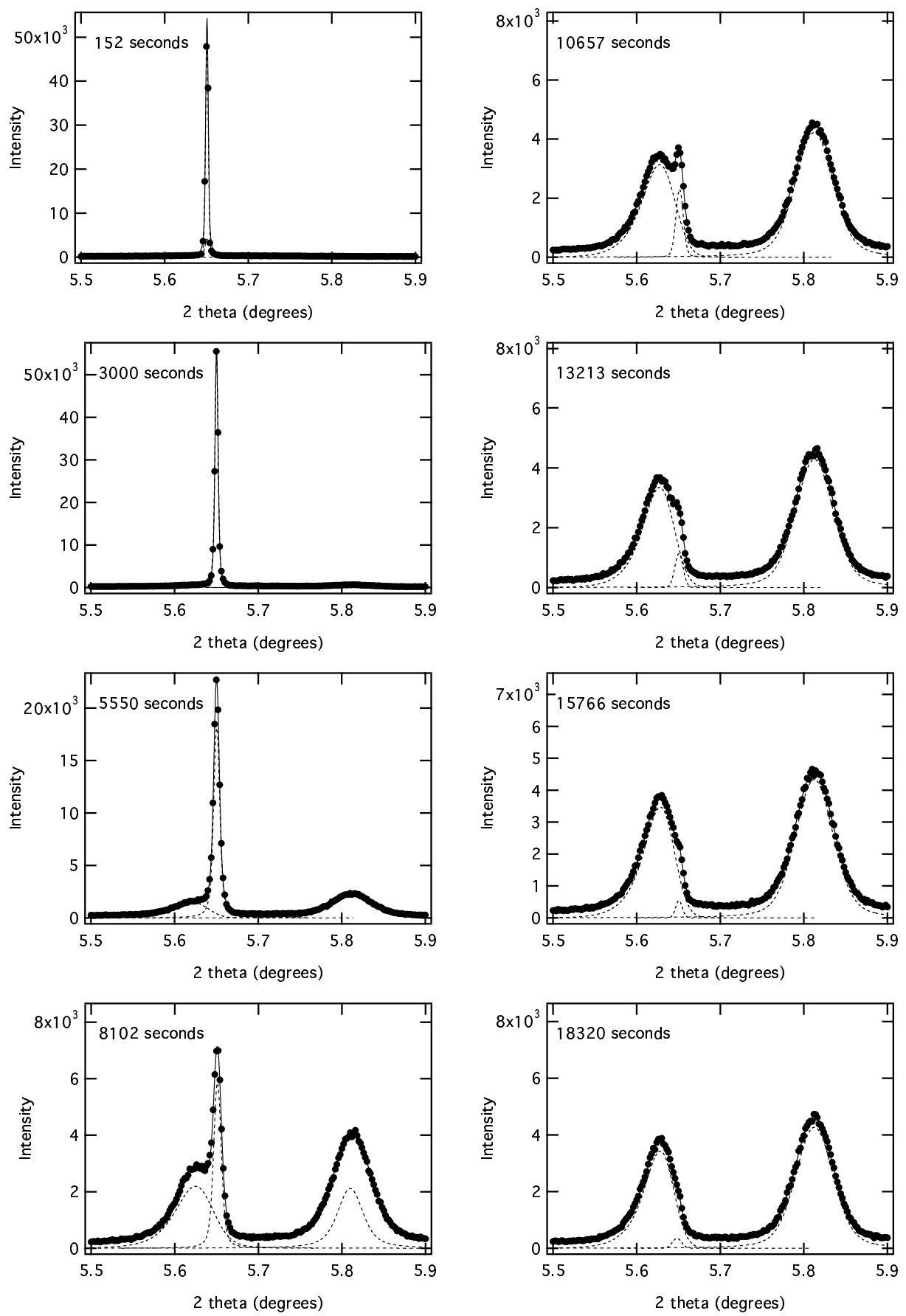

Figure 6. Austenite $\{111\}$ and ferrite $\{110\}$ reflections during isothermal transformation. Solid lines represent the fit achieved; the individual peak profiles less the background are the dotted lines. 


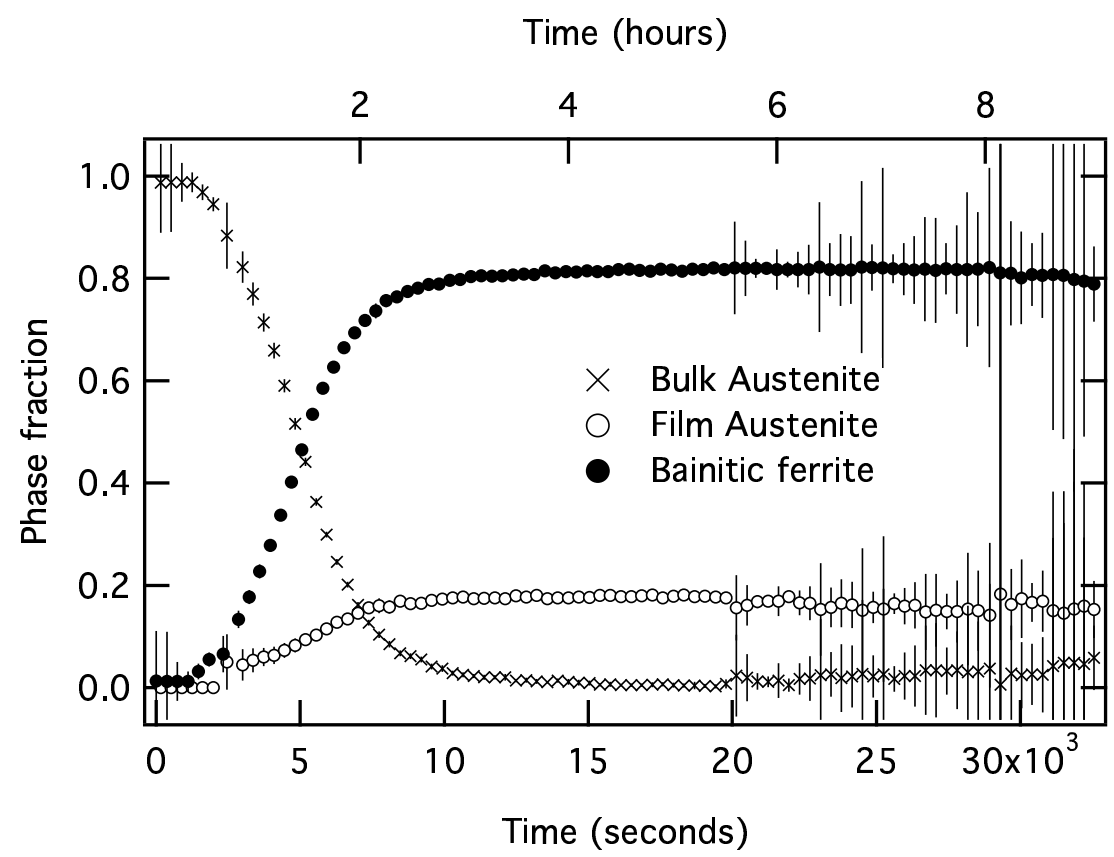

Figure 7. Fractions of the ferrite and both austenite populations during transformation at $300^{\circ} \mathrm{C}$. The larger error bars towards the end of transformation come from the uncertainty in fitting the bulk austenite as its fraction tends towards zero. Uncertainty in the fitting of any peak reflects in all the others. The larger errors bars are therefore due to the fitting of the vanishing phase and do not provide a fair reflection of the actual uncertainty in the fractions of the film austenite and baintic ferrite. 


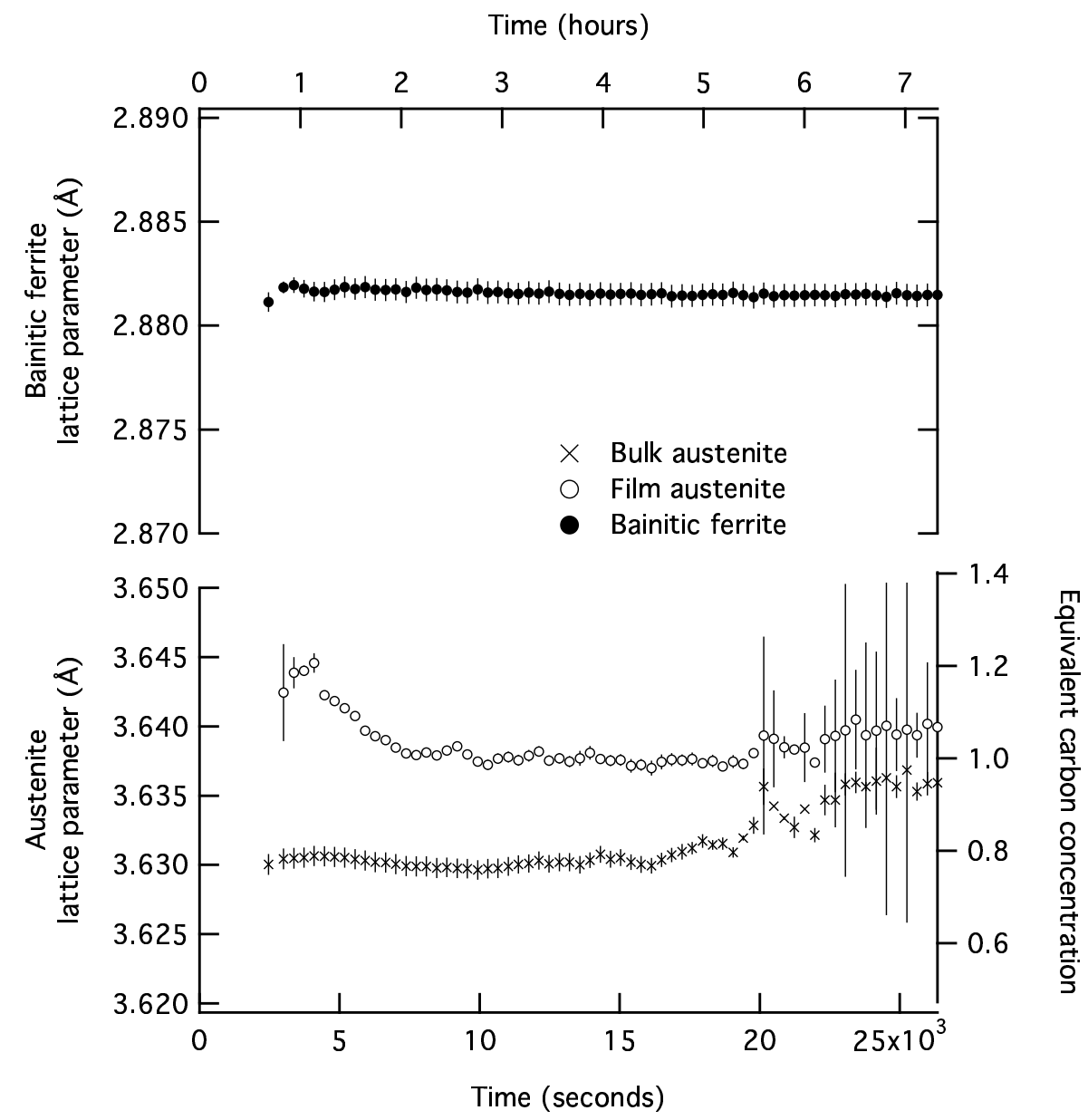

Figure 8. Lattice parameters of the bainitic ferrite and austenite populations during isothermal hold at $300^{\circ} \mathrm{C}$ after austenitisation. The equivalent carbon concentrations for the two populations of austenite are also included. 


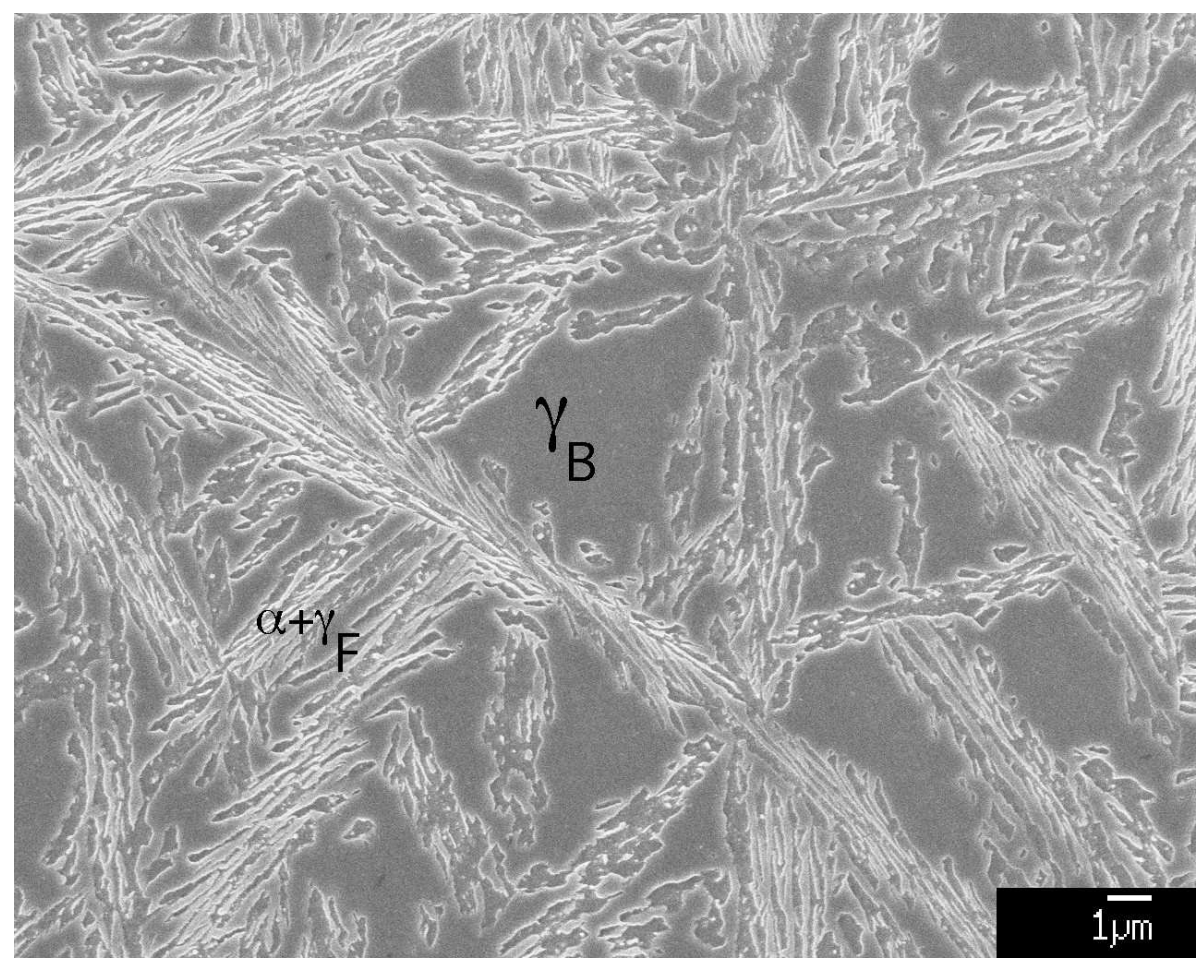

Figure 9. Microstructure after cessation of isothermal transformation. $\gamma_{B}$ represents the blocks of austenite, and $\alpha+\gamma_{F}$ the mixture of bainitic ferrite and films of austenite.

Proceedings of the Royal Society A, Vol. 464, 2008, 1009-1027. 

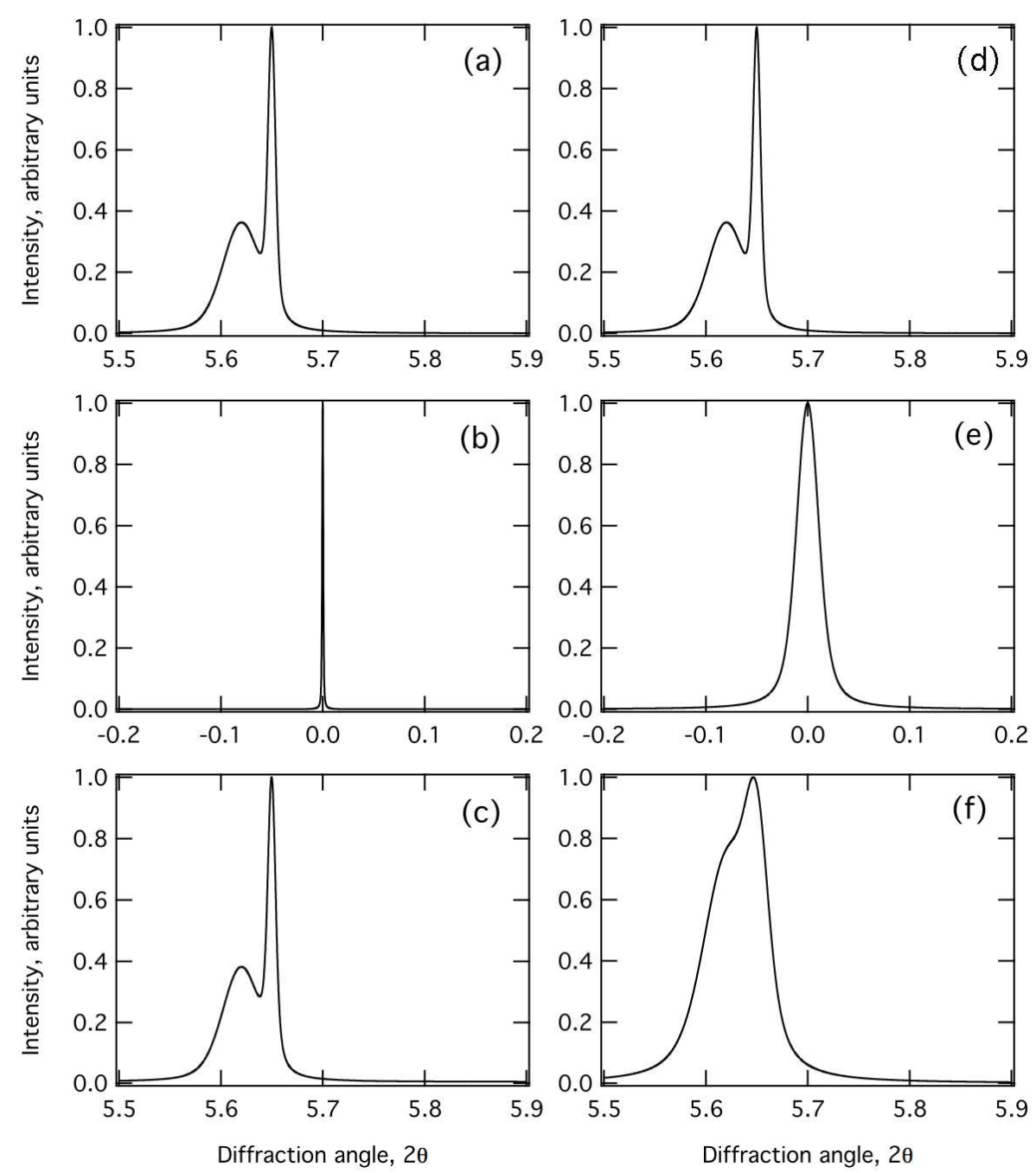

Figure 10. Simulation of the effect of resolution on observed data. (a) and (d) represent a perfect observation. (b) and (e) represent estimated instrument resolution functions consistent with the resolution in the present and previous work respectively. (c) and (f) the effect of convolving the ideal observation with the resolution. 


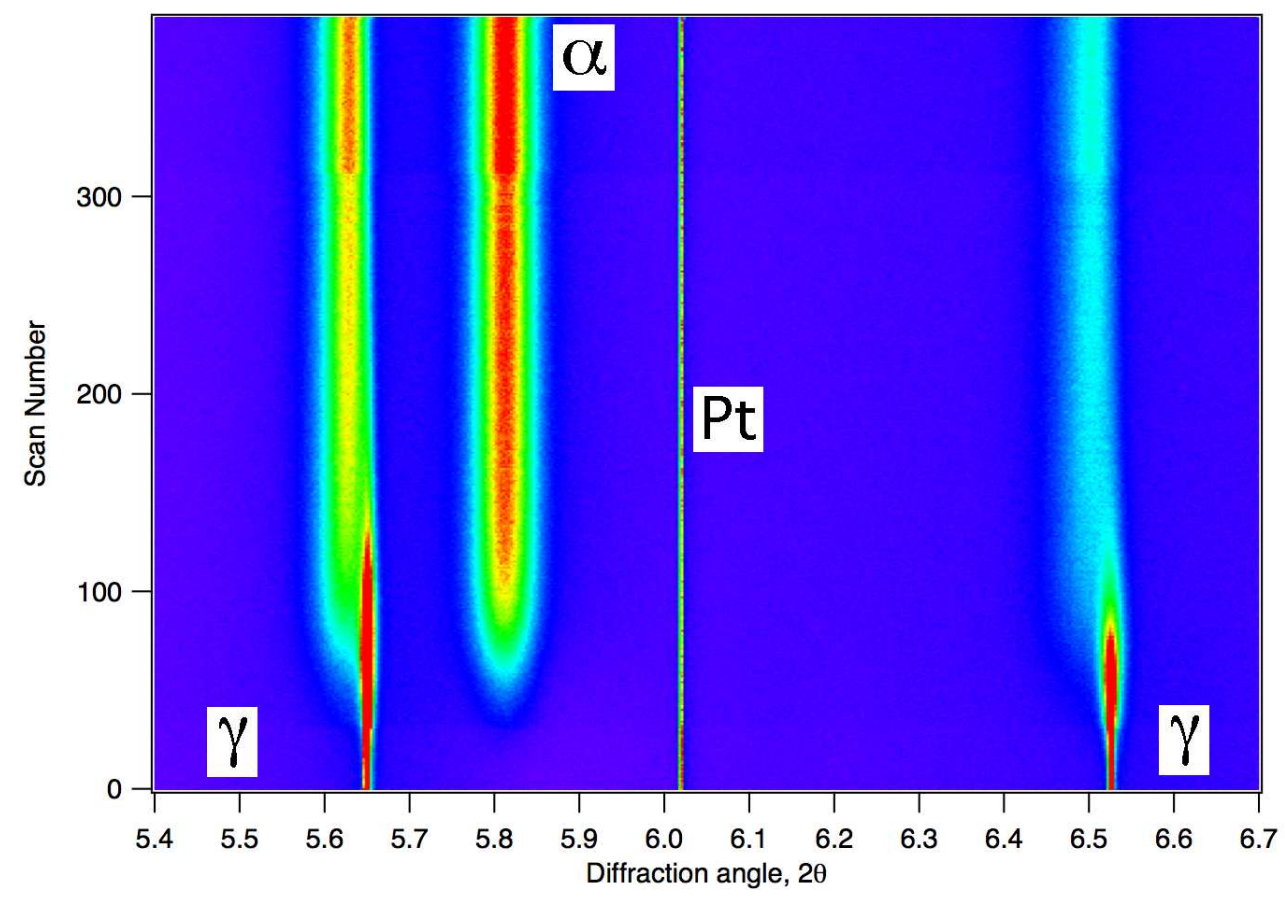

Figure 11. Isothermal diffraction scan data presented as a colour map showing austenite $\{111\}$ and ferrite $\{110\}, \mathrm{Pt}$ and austenite $\{002\}$ peaks during isothermal heat-treatment at $300^{\circ} \mathrm{C}$ following austenitisation. 


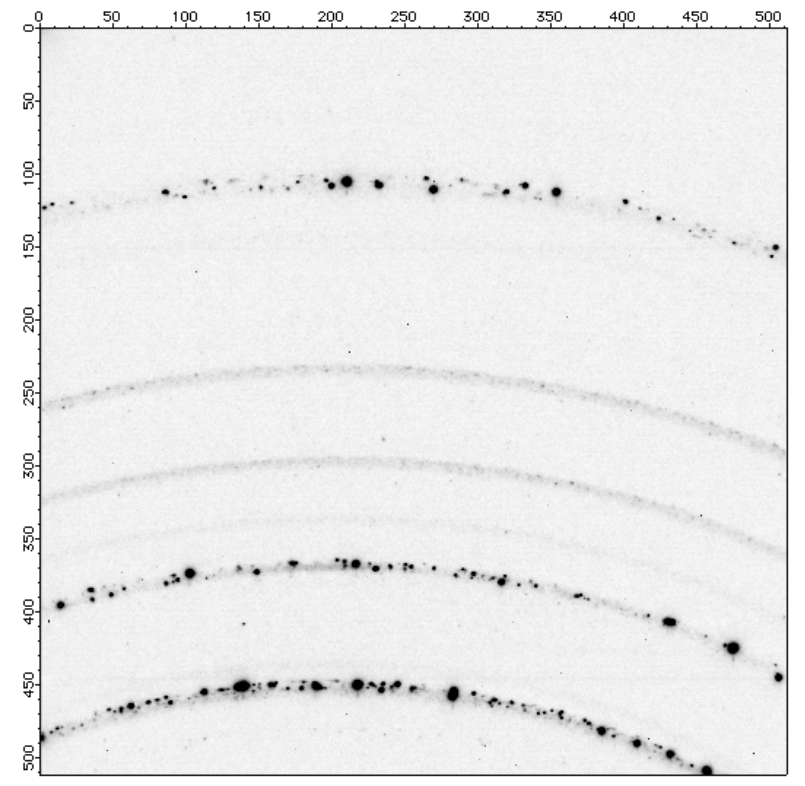

Figure 12. APS Diffraction data from austenite prior to its transformation; starting from the bottom, the rings correspond to $111 \gamma, 002_{\gamma}, 224_{M}, 151_{M}, 404_{M}$ and $220_{\gamma}$, where the subscript $M$, refers to magnetite $\left(\mathrm{Fe}_{3} \mathrm{O}_{4}\right)$ (Babu et al., 2005).

Proceedings of the Royal Society A, Vol. 464, 2008, 1009-1027. 

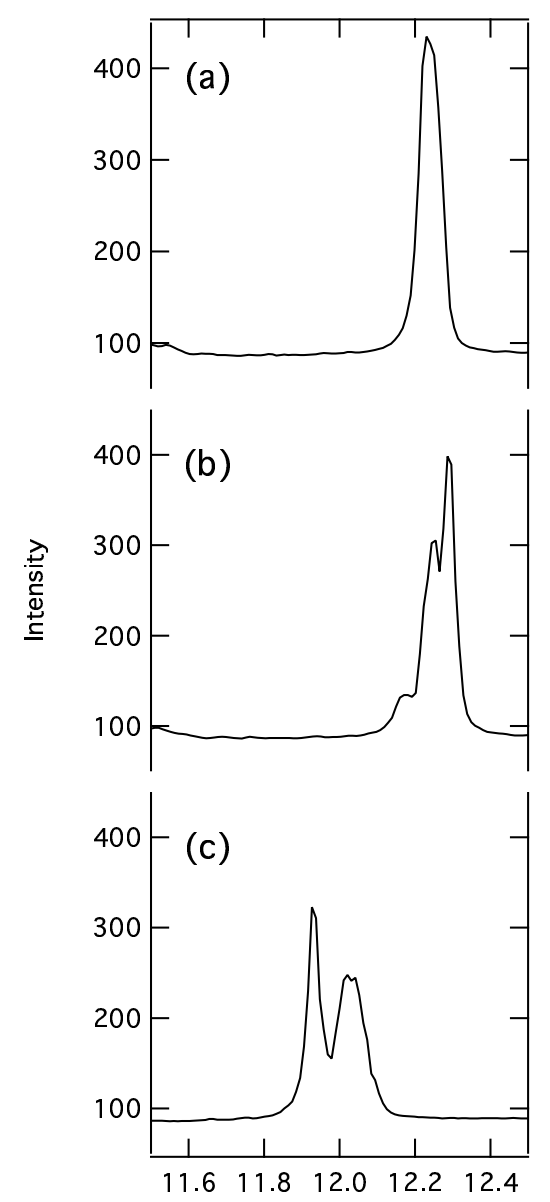

(a)

Diffraction angle $-2 \theta\left({ }^{\circ}\right)$

(d)

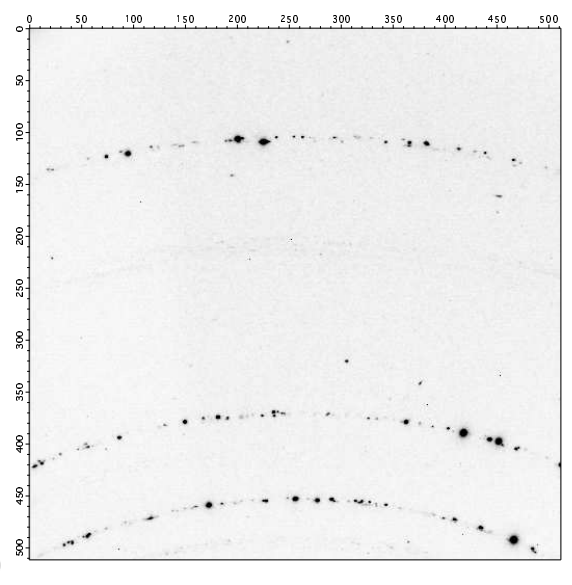

Figure 13. Analysis of the $111_{\gamma}$ data on Fe-Ni-C system (Babu et al., 2007). (a) A good integration. (b) With beam-centre distortion. (c) With tilt distortion. (d) Data on which $\mathrm{a}-\mathrm{c}$ are based (scales in pixels). 
(a)

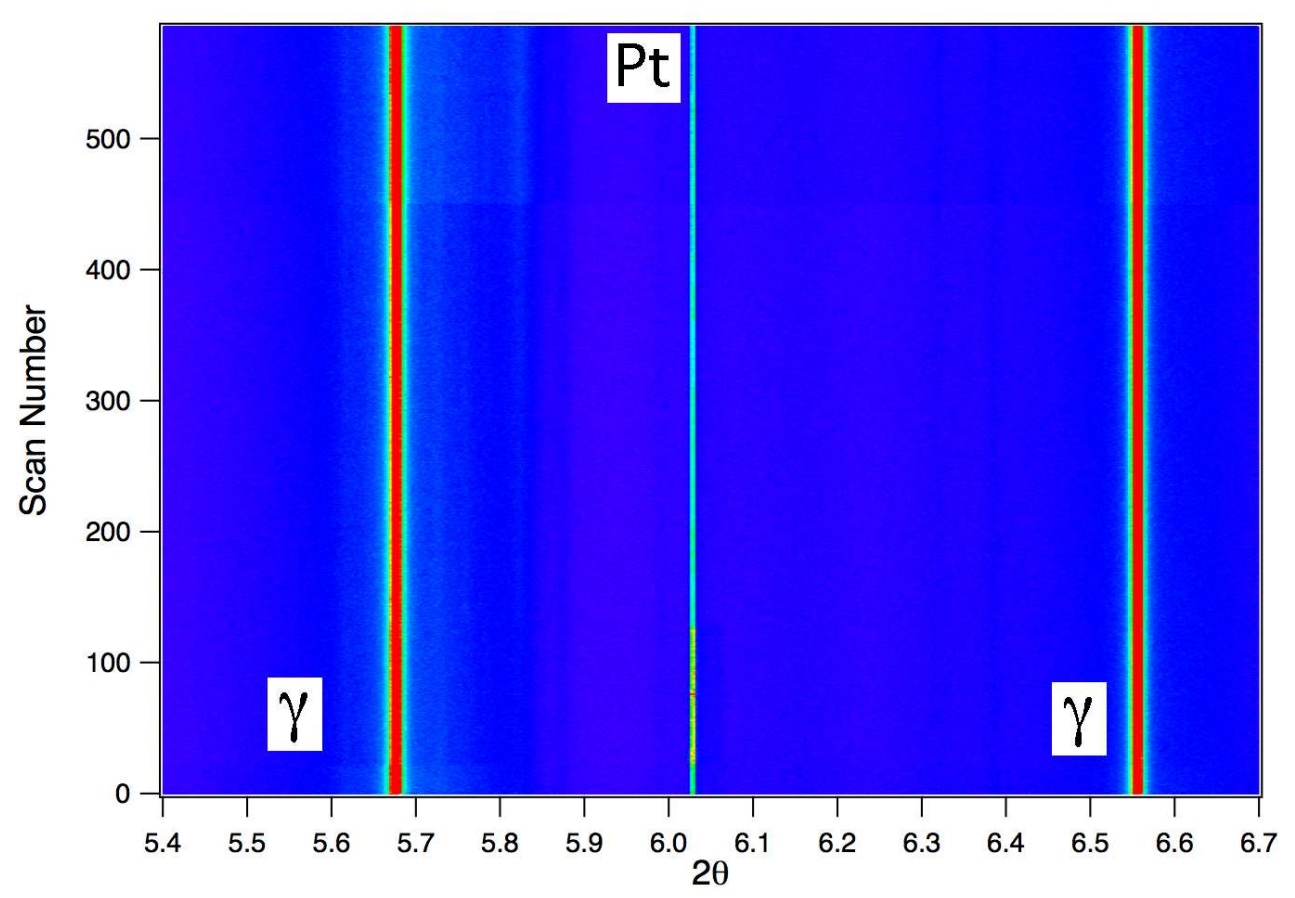

(b)

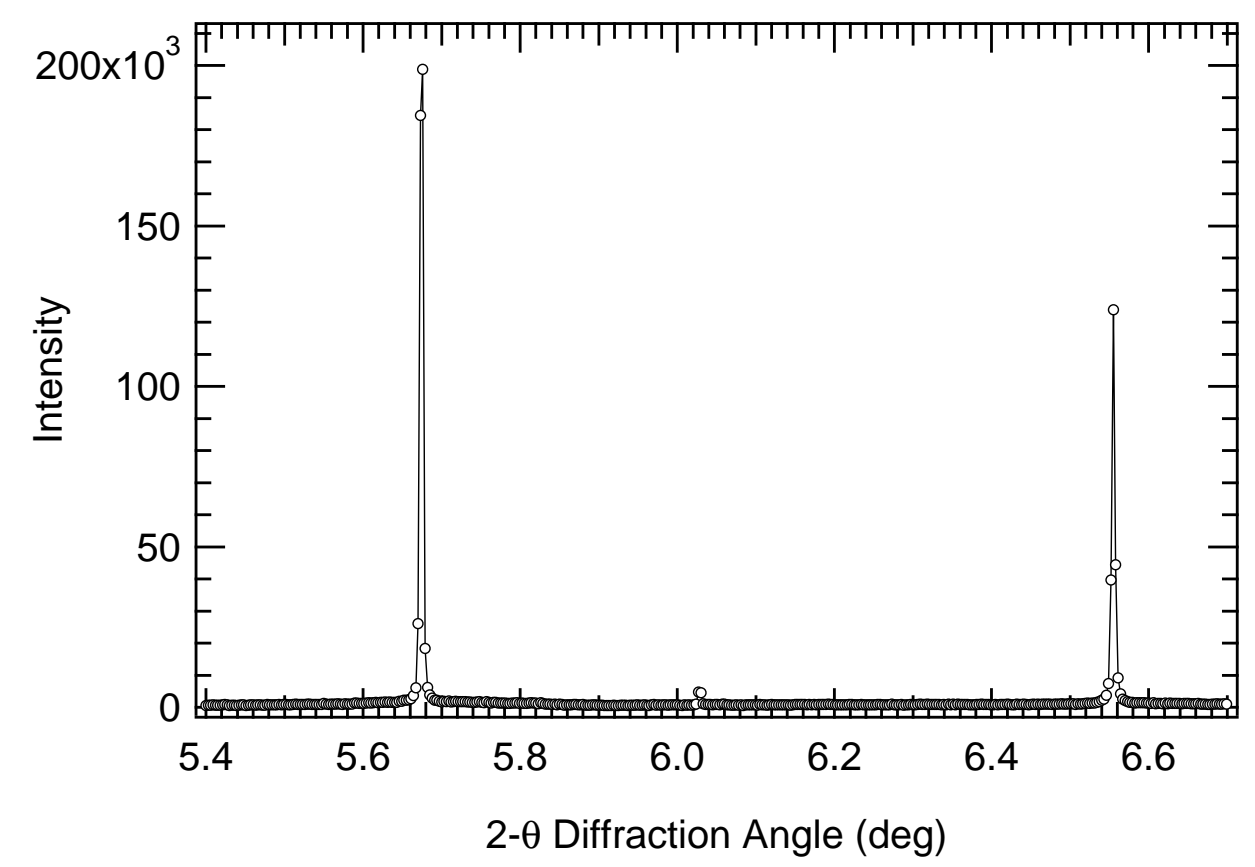

Figure 14. Isothermal heat-treatment of Alloy 2 at $200^{\circ} \mathrm{C}$ showing a ten hour span in which only austenite is present.

Proceedings of the Royal Society A, Vol. 464, 2008, 1009-102\%. 